\title{
A social work study on the effects of self-esteem games on elementary female self-esteem
}

\author{
Samaneh Moein ${ }^{a^{*}}$, Mohammad Reza Abedi ${ }^{\mathrm{b}}$ and Iran Baghban ${ }^{\mathrm{b}}$
}

${ }^{a}$ MA Student of Career Counseling, Department of Counseling, faculty of Psychology, University of Isfahan, Isfahan, Iran ${ }^{b}$ PhD of Counseling, Department of Counseling, faculty of Psychology, University of Isfahan, Isfahan, Iran

\section{CHR ON I C L E}

\section{Article history:}

Received May 18, 2013

Received in revised format

28 August 2013

Accepted 1 September 2013

Available online

September 12013

Keywords:

Self-esteem games

Self-esteem

Elementary schools

\section{A B S T R A C T}

Researchers and clinicians from many disciplines are interested in learning more about the effects of self-esteem. Self-esteem affects motivation, functional behavior, and life satisfaction, and it is associated with well-being throughout life, significantly. What individuals choose to do and the way they do it in part may depend on their selfesteem and it can also fulfill the aims of mental health. This paper presents an investigation to determine the effect of play on children's self-esteem and surveys appropriate interventions in this area. This study was semi experimental and the sample was $3^{\text {rd }}$ grade elementary students who were randomly assigned into control $(n=15)$ and experimental $(n=15)$ groups. The instrument was Rosenberg self-esteem scale [Rosenberg, M. (1965). Rosenberg self-esteem scale (RSE). Acceptance and Commitment Therapy. Measures Package, 61.]. Independent variable was 12 group sessions of self-esteem games executed among experimental group. Data was analyzed with univariate analysis of covariance. Results showed that self-esteem games in $\alpha \leq 0.05$ were affected on self-esteem of children. Self-esteem game can be effective intervention for children self-esteem that with them control of factors such as time and children interactions with parent and teachers in future investigations could lead to greater confidence in its effectiveness discussed.

\section{Introduction}

Self-esteem plays essential role on people's lives since it influences motivation, functional behavior, and life satisfaction, and it is associated with well-being throughout life, significantly (Chazan, 2002). There are literally various studies associated with the effects of self-esteem on different groups of communities (Plummer, 2001, 2007; Dougherty, 2006). Ajilchi et al. (2011) performed a survey on 250 elementary school children and their mothers. They first screened the mothers based on the

*Corresponding author. Tel: +989139045054

E-mail address: samaneh.moein@yahoo.com (S. Moein) 
Parenting Stress Index (PSI), selected 80 overstressed mothers and assigned 38 mothers randomly into either the experimental group or the control group. The PSI and Coopersmith Self- Esteem Inventory (CESI) were implemented before and following training to measure the effect of the parenting skills training program on the mothers and their children, whose average age was 10.6 years. They reported that the self-esteem level of children could increase after 8 training sessions, significantly.

According to Bratton et al. (2005), the efficacy of psychological interventions for children has been controversial debates among mental health professionals. Play therapy is a developmentally responsive intervention widely implemented by child therapists but normally criticized for insufficient research base to support its growing practice. Bratton et al. (2005) considered an analysis of 93 controlled outcome studies, published 1953-2000, to evaluate the overall efficacy of play therapy and to detect factors that might influence its effectiveness. The overall treatment impact for play therapy interventions was 0.80 standard deviations. They reported that impacts were more positive for humanistic than for nonhumanistic treatments and that using parents in play therapy generated the largest impacts. In their reported, play therapy seemed equally effective across age, gender, and presenting issue.

Khorshidi Mehr et al. (2011) investigated whether primary school plays (Fromberg \& Bergen, 1998; Lindon, 2001) could provide primary school students with settings for development to gain selfknowledge or evaluate their own characteristics. The investigation was quasi-experimental and contained a pre-post-test design and a group of primary school students as its statistical population. The study consisted of 30 students, randomly chosen and divided into two groups of control and experimental. Pep test. 5-scale test was applied to study pre and post-game self-esteem of students. Independent $t$ was implemented at the significance level of $\mathrm{p} \leq 0.05$ to examine the research hypotheses. The result stated that an 8 -week period of playing primary school plays maintained a positive and significant impact on personal self-esteem, social self-esteem and self-esteem. However, no significant impact was detected on family and educational self-esteem. They concluded that playing primary school plays may boost students' self-knowledge and self-appraisal and it could provide them with a positive attitude towards their own beings.

According to Maxwell and Chmielewski (2008) some studies indicate that the physical classroom environment had the potential to influence children's behaviors, academic performance, and cognitive development. Maxwell and Chmielewski (2008) investigated the potential impact of one of the characteristics of the classroom's physical environment, personalization displays, on children's selfesteem. The study used a classroom intervention in a quasi-experiment to study the impacts of increasing environmental personalization on children's self-esteem. They performed their assessment on 38 kindergarteners and first graders in 6 classrooms of two elementary schools in a rural community of a north-eastern on pre-tests and post-tests of the Self-Esteem Index (SEI) scale and the Children's Inventory of Self-Esteem (CISE) scale (Mruk, 2006). They reported a significant positive impact of classroom personalization for first graders. However, for kindergarteners there was a substantial positive impact for only one measure, the CISE.

Saadat et al. (2012) studied the relationship between self-esteem and locus of control (Martino, 2009) of university students. They reported a positive and meaningful relationship between all self-esteem components and internal locus of control based on the results obtained from a study on 370 students. However, the relationship became negative while talking about external and chance kinds.

\section{The proposed study}

This paper presents an investigation to determine the effect of play on children's self-esteem and surveys appropriate interventions in this area. This study was semi experimental and the sample was 
3rd grade elementary students who were randomly assigned into control $(n=15)$ and experimental $(\mathrm{n}=15)$ groups. The instrument was Rosenberg self-esteem scale (Rosenberg, 1965). Independent variable was 12 group sessions of self-esteem games executed among experimental group. Data was analyzed with univariate analysis of covariance. Table 1 demonstrates some basic statistics on the gathered data.

\section{Table 1}

The summary of some basic statistics

\begin{tabular}{lllc}
\hline Stage & Group & Mean & Standard deviation \\
\hline \multirow{3}{*}{ Pre-test } & Experiment & 24.21 & 4.78 \\
& Witness & 21.93 & 4.06 \\
\hline \multirow{3}{*}{ Post-test } & Total & 23.07 & 4.51 \\
& Experiment & 24.60 & 3.18 \\
& Witness & 20.13 & 4.98 \\
\hline
\end{tabular}

The first step to verify the information is to find out whether the data are normally distributed or not. The proposed study of this paper uses Kolmogorov-Smirnov and Shapiro-Wilk tests to verify this. Table 2 summarizes the results of our survey on normality test.

Table 2

The summary of Kolmogorov-Smirnov and Shapiro-Wilk tests

\begin{tabular}{llcccccc}
\hline & & \multicolumn{3}{c}{ Shapiro-Wilk } & \multicolumn{3}{c}{ Kolmogorov-Smirnov } \\
Variable & Group & Statistics & df & Sig. & Statistics & df & Sig. \\
\hline Self-esteem & Experiment & 0.928 & 14 & 0.285 & 0.149 & 14 & 0.200 \\
& Witness & 0.919 & 14 & 0.215 & 0.175 & 14 & 0.200 \\
\hline
\end{tabular}

The null hypothesis of both tests is that the data are normally distributed and according to Sig. value we can accept both null hypotheses and conclude that the data are normally distributed. Next, we need to make sure that the gathered data maintain homogeneous variance and this could be accomplished through Levin test. Table 3 demonstrates the summary of our survey.

Table 3

The summary of Levin test

\begin{tabular}{lcccc}
\hline Variable & F-value & df between group & df of Error & Sig. \\
\hline Self-esteem & 1.72 & 1 & 26 & 0.20
\end{tabular}

The results of Table 3 show that the variances are homogeneous and we can use analysis of variance (ANOVA) on the data, which are summarized in Table 4 as follows,

\section{Table 4}

The summary of ANOVA test

\begin{tabular}{|c|c|c|c|c|c|c|c|}
\hline Source of change & Dependent variable & Sum of squares & df & Mean of Squares & $\mathrm{F}$ & Sig. & $\eta^{2}$ \\
\hline Member & Self-esteem & 60.17 & 1 & 60.17 & 4.22 & 0.05 & 0.14 \\
\hline Group & Error & 356.56 & 25 & 14.26 & & & \\
\hline
\end{tabular}

The results of Table 4 indicate that there is a meaningful difference between two groups of experiment and witness when the level of significance is five percent. 


\section{Conclusion}

This paper has presented an investigation to determine the effect of play on children's self-esteem and surveys appropriate interventions in this area. The instrument was Rosenberg self-esteem scale where independent variable was 12 group sessions of self-esteem games executed among experimental group. Data was analyzed with univariate analysis of covariance. Results showed that self-esteem games in $\alpha \leq 0.05$ were affected on self-esteem of children. Self-esteem game could be effective intervention for children self-esteem that with them control of factors such as time and children interactions with parent and teachers in future investigations could lead to greater confidence in its effectiveness discussed.

\section{References}

Ajilchi, B., Borjali, A., \& Janbozorgi, M. (2011). The impact of a parenting skills training program on stressed mothers and their children's self-esteem level. Procedia - Social and Behavioral Sciences, $30,316-326$.

Bratton, S. C., Ray, D., Rhine, T., \& Jones, L. (2005). The efficacy of play therapy with children: A meta-analytic review of treatment outcomes. Professional Psychology: Research and Practice, 36(4), 376-390.

Chazan, S.E. (2002) Profiles of Play Assessing and Observing Structure and Process in Play Therapy. London and New York: Jessica Kingsley Publishers.

Dougherty, J.L. (2006). Impact of child-centered play therapy on children of different developmental stages. A Thesis Submitted to the University of North Texas for Doctor of Philosophy.

Fromberg, D.P., \& Bergen, D. (1998). Play from Birth to Twelve and Beyond (Contexts, Perspectives and Meanings).New York \& London: Garland Publishing, Inc.

Khorshidi Mehr, M., Sajadian, M. \& Saiiari, Abdulamir. (2011). A study of impact of primary school games on the self-esteem of female students aged 9-11 of Ahvaz primary schools. Procedia Social and Behavioral Sciences, 30, 2357 - 2360.

Lindon, J. (2001).Understanding Children's Play. Cheltenham: Nelson Thornes Ltd Publication.

Martino, J.M. (2009). Primary Caregivers' Values of Play and Creativity in Early Childhood in Relation to Children's Academic Self-esteem. Thesis submitted to the College of Human Resources and Education at West Virginia University in partial fulfillment of the requirements for the degree of Master of Arts In Educational Psychology With an emphasis in Child Development and Family Studies.

Maxwell, L.E. \& Chmielewski, E.J. (2008). Environmental personalization and elementary school children's self-esteem. Journal of Environmental Psychology, 28, 143-153.

Mruk, C. J. (2006). Self-esteem research, theory, and practice: toward a positive psychology of selfesteem (3th Ed). New York: Springer Publishing Company, Inc.

Plummer, D.M. (2007). Self-Esteem Games for Children. London and Philadelphia: Jessica Kingsley Publishers.

Plummer, D.M. (2001). Helping Children to Build Self-Esteem. London and Philadelphia: Jessica Kingsley Publishers.

Rosenberg, M. (1965). Rosenberg self-esteem scale (RSE). Acceptance and Commitment Therapy. Measures Package, 61.

Saadat, M., Ghasemzadeh, A., Karami, S., Soleimani, M. (2012). Relationship between self-esteem and locus of control in Iranian University students. Procedia - Social and Behavioral Sciences, 31, $530-535$

VanFleet, R., Sywulak, A.E. \& Sniscak, C.C. (2010). Child-Centered Play Therapy. New York, London: Guilford Publications, Inc. 